\title{
VECM Model Analysis of Carbon Emissions, GDP, and International Crude Oil Prices
}

\author{
Xiaohua Zou (iD) \\ Changzhou College of Information Technology, Changzhou 213100, China \\ Correspondence should be addressed to Xiaohua Zou; xhua.zou@163.com
}

Received 14 March 2018; Revised 23 June 2018; Accepted 4 July 2018; Published 1 August 2018

Academic Editor: Emilio Jiménez Macías

Copyright (C) 2018 Xiaohua Zou. This is an open access article distributed under the Creative Commons Attribution License, which permits unrestricted use, distribution, and reproduction in any medium, provided the original work is properly cited.

\begin{abstract}
As a kind of scarce natural capital, energy makes more and more obvious constraint effects on economic growth. And energy consumption is the major source of greenhouse gas emissions. This brings about the problems of the relationships among energy consumption, carbon emissions, and economic growth, which is worthy of long-term attention. This paper attempted to explore the interactive relations among American oil prices, carbon emissions, and GDP through the data analysis from 1983 to 2013 . This paper adopted time series vector error correction model (VECM) approach to conduct stationarity test, cointegration test, stability test, and Granger causality test. The results indicated that, no matter in the short term or long term, oil price fluctuation is the reason why carbon emissions change, while the GDP fluctuation is not the reason for the growth of carbon emissions. The oil price impacts will have a great influence on GDP and carbon emissions in the short term, but, the in long term, the influence will tend to be gentle.
\end{abstract}

\section{Introduction}

Global warming caused by greenhouse effect has become one of the major concerns for human survival. Some scientists predict that if humans do not take immediate measures to reduce greenhouse gas emissions, it is possible that surface temperature of the earth will increase by $4^{\circ} \mathrm{C}$ as early as 2050. This can lead to adverse weather and sea level rise of at least dozens of meters. And series of catastrophes may bring about the coming of "the end of the world" described in movies. Some researches show that greenhouse effect mainly attributes to excessive use of fossil energy in modern industrial society and the massive emission of carbon dioxide gas into the atmosphere.

Since the 1990s, the international community had recognized the seriousness of global warming issue and argued that the reduction of greenhouse gas emissions, especially $\mathrm{CO}_{2}$, is the best way to solve global climatic and ecological issues. And some measures gradually come into use in order to reduce carbon emissions. However, economic development cannot be separated from energy consumption. As a kind of scarce natural capital, energy presents more and more obvious constraint effects on economic growth.
And energy consumption is the major source of greenhouse gas emissions. This brings about the problems of the relationships among energy consumption, carbon emissions, and economic growth, which is worthy of long-term attention.

Empirical study on the relationship between energy consumption and economic growth began in the 1970s. J. Kraft and A. Kraft [1] firstly conducted a pioneering research on the relationship between energy consumption and economic growth in 1978, based on the data of the US from 1947 to 1974, and found the one-way causal relationship between GNP and energy consumption; namely, economic growth could drive the increase of energy consumption. At present, common research methods adopted to study on this issue can be mainly classified into two categories. The first one is the Kuznets curve method. For example, Hiroki Iwata et al. [2] proved the existence of inverted "U" type "environmental Kuznets curve (EKC)" through an empirical analysis of France's carbon dioxide emissions. $\mathrm{Wu}$ Zhenxin et al. [3] supplemented the factor of industrial structure based on environmental Kuznets curve (EKC) and established the individual fixed effect model based on the panel data of 30 provinces in China from 2000 to 2009, 
to explore the effects of economic growth and industrial structure on carbon emissions. The results showed that there respectively existed cointegration relations between carbon emissions and economic growth, as well as between carbon emissions and industrial structure; the relationship between carbon emissions and economic growth presented inverted "U" type characteristics. Lin Boqiang et al. [4] put forward the Kuznets curve of $\mathrm{CO}_{2}$ emissions by the method of time series analysis and forecast China's $\mathrm{CO}_{2}$ emissions in the future. Ren Zhong and Zhou Yunbo [5] investigated the relationship between per capita GDP and industrial waste gas emissions in the Bohai Rim region and argued that the relationship between the two factors showed overall upward inverted "N" type curve characteristics.

The second one is the regression model method. For instance, Ugur Soytas et al. [6] studied the Granger causality relationships among the US income, energy consumption, and carbon emissions based on the Vector Autoregression Model (VAR). In this model, labor force and gross fixed capital were taken into account. It was found that, in the long run, income is not the Granger cause of carbon emissions, so income itself could not become a means to solve environmental problems. Niaz Bashiri Behmiri et al. [7] discussed the influences of changes in crude oil prices, natural gas prices, coal prices, and electricity prices on carbon dioxide emission quota price distribution in the US, on the basis of the quantile regression model. It was indicated that, in the condition of high carbon prices, the price increasing of crude oil would cause the sharp drop in carbon prices. Shawka Hammoudeh et al. [8] utilized VAR and VECM (vector error correction model) to analyze the short-term dynamic influence of changes in oil prices, coal prices, natural gas prices, electricity prices, and carbon emissions quota on carbon emissions prices. One important found conclusion is that a positive impact of the crude oil price will produce a negative effect on the approved price of carbon emissions. Meanwhile, they discovered that energy price impacts will have continual influence on the approved price of carbon emissions. Rajaratnam Shanthini [9] demonstrated the longterm equilibrium relationship between $\mathrm{CO}_{2}$ emissions and GDP (i.e., $1 \%$ increase in GDP led to $3.2 \%$ increase in $\mathrm{CO}_{2}$ emissions), via marginal testing method of the autoregressive distributed lag model. Furthermore, it was revealed that long-term decrease of $\mathrm{CO}_{2}$ emissions was related to price increasing of crude oil and technical progress, despite their small extent. Min Jisheng and Hu Hao [10] examined the dynamic evolution relationship between China's carbon emissions and economic growth between 1994 and 2007 by means of the VAR method and proposed that economic growth was the main reason of carbon emission increasing. Economic growth led to the rising of carbon emissions, and the increasing of carbon emissions reversely inhibited the rate of economic growth, with certain lag period. Jing Luo [11] conducted an empirical research on the alterable relation between China's per capita GDP and carbon dioxide emissions. He adopted the time series data from 1978 to 2008 on the basis of the optimal regression model, to reveal the long-term and short-term influence of China's economic growth on carbon dioxide emissions. Fu Jiafeng
[12] examined the correlation between $\mathrm{CO}_{2}$ emissions per unit of GDP and GDP per capita, collecting the panel data of 44 countries between 1990 and 2004. The study indicated that EKC existed between the two factors. Han Yujun [13] carried out an empirical analysis based on the data from 165 countries, and maintained that EKC differed among countries with different income levels. Zhang Xingping et al. [14] utilized the multivariable model, considering the economic growth, energy usage, carbon emissions, capital and city population, to survey the existence and effects of Granger causal relationships among China's economic growth, energy consumption, and carbon emissions. The research showed that, within the past 47 years in China, the economic growth was not caused by carbon emissions or energy consumption. From this, it can be presumed that the conservative energy policies and emission reduction policies which adopted by Chinese government will not impede the economic growth in the long run.

It can be seen that regression models are commonly utilized to study energy and economy problems, and research contents mostly concentrate upon the correlation among energy consumption, carbon prices, carbon emissions quota, and other aspects. However, there is no relevant literature which directly studies the three aspects of actual carbon emissions, oil prices, and GDP. Therefore, this paper took the US as an example to study volatility transmission mechanism of a closed economy and the interactive relationships among oil prices, GDP, and carbon emissions, with the VEC model. Primary energy carbon emissions, gross domestic product (GDP), and international crude oil prices from 1983 to 2013 in the US were selected as sample data to evaluate whether there was cointegration relationship based on the VAR model, and the VEC model was also built. In this paper, the main study objectives were as follows: (1) to analyze whether the three variables have cointegration relationship, i.e., whether there is a long-term equilibrium relationship; (2) to test whether there is a causal relationship among the three variables; (3) to establish an impulse response function to describe short-term dynamic relationship over time among the three variables based on the VEC model.

\section{VECM}

Modern econometricians point out a method to establish the relational model among economic variables in a nonstructural way. They are vector autoregressive model (VAR) and vector error correction model (VEC).

The VAR model is established based on the statistical properties of data. In the VAR model, each endogenous variable in the system is considered as the lagged value of all endogenous variables in the system; thus the univariate autoregressive model is generalized to the "vector" autoregressive model consisting of multivariate time series variables. In 1980, Sims (Christopher Sims) introduced VAR model into economic field and promoted the widespread application in dynamic analysis of economic system. 
Engle and Granger combined cointegration and error correction models, to establish the trace error correction model. As long as there is a cointegration relationship between variables, the error correction model can be derived from the autoregressive distributed lag model. And each equation in the VAR model is an autoregressive distributed lag model; therefore, it can be considered that the VEC model is a VAR model with cointegration constraints. Because there is a cointegration relationship in the VEC model, when there is a large range of short-term dynamic fluctuation, VEC expressions can restrict long-term behavior of the endogenous variables and be convergent to their cointegration relation.

Assuming $\mathrm{y}_{\mathrm{t}}=\left(\mathrm{y}_{1 \mathrm{t}}, \mathrm{y}_{2 \mathrm{t}}, \ldots, \mathrm{y}_{\mathrm{kt}}\right)^{\prime}$ as k-dimensional stochastic time series, $\mathrm{t}=1,2, \ldots, \mathrm{T}$ and $\mathrm{y}_{\mathrm{t}} \sim \mathrm{I}(1)$, each $y_{\text {it }} \sim \mathrm{I}(1), \mathrm{i}=1,2, \ldots, \mathrm{k}$ is affected by exogenous time series of d-dimension $\mathrm{x}_{\mathrm{t}}=\left(\mathrm{x}_{1 \mathrm{t}}, \mathrm{x}_{2 \mathrm{t}}, \ldots, \mathrm{x}_{\mathrm{dt}}\right)^{\prime}$; then the VAR model can be established as follows:

$$
\begin{array}{r}
y_{t}=A_{1} y_{t-1}+A_{2} y_{t-2}+\cdots+A_{p} y_{t-p}+B x_{t}+\mu_{t}, \\
t=1,2, \ldots, T
\end{array}
$$

If $y_{t}$ is not affected by exogenous time series of $d$ dimension $\mathrm{x}_{\mathrm{t}}=\left(\mathrm{x}_{1 \mathrm{t}}, \mathrm{x}_{2 \mathrm{t}}, \ldots, \mathrm{x}_{\mathrm{dt}}\right)^{\prime}$, then the VAR model of formula (1) can be written as follows:

$$
\begin{aligned}
y_{t}=A_{1} y_{t-1}+A_{2} y_{t-2}+\cdots+A_{p} y_{t-p}+\mu_{t} & \\
& t=1,2, \ldots, T
\end{aligned}
$$

With cointegration transformation of formula (2), we can get that

$$
\Delta y_{t}=\prod y_{t-1}+\sum_{i=1}^{p-1} \Gamma_{i} \Delta y_{t-i}+\mu_{t}
$$

where

$$
\begin{gathered}
\prod=\sum_{i=1}^{p} A_{i}-I, \\
\Gamma_{i}=-\sum_{j=i+1}^{p} A_{j}
\end{gathered}
$$

If $y_{t}$ has cointegration relationship, then $\prod y_{t-1} \sim \mathrm{I}(0)$ and formula (3) can be written as follows:

$$
\Delta y_{t}=\alpha \beta^{\prime} y_{t-1}+\sum_{i=1}^{p-1} \Gamma_{i} \Delta y_{t-i}+\mu_{t}
$$

where $\beta^{\prime} \mathrm{y}_{\mathrm{t}-1}=\mathrm{ecm}_{\mathrm{t}-1}$ is the error correction term, which reflects long-term equilibrium relationships between variables, and the above formula can be written as follows:

$$
\Delta y_{t}=\alpha e c m_{t-1}+\sum_{i=1}^{p-1} \Gamma_{i} \Delta y_{t-i}+\mu_{t}
$$

Formula (6) is the vector error correction model (VECM), in which each equation is an error correction model.
TABLE 1: Unit root test results of sequence level values.

\begin{tabular}{lcc}
\hline Variable & $\begin{array}{c}\text { ADF } \\
\text { Level }\end{array}$ & $\begin{array}{c}\text { PP } \\
\text { Level }\end{array}$ \\
\hline$c p_{t}$ & $-2.403899(0.1492)$ & $-4.542207(0.0003)$ \\
\hline$o p_{t}$ & $-0.557236(0.8746)$ & $-0.413474(0.9022)$ \\
\hline$g d p_{t}$ & $1.983083(0.9999)$ & $2.061330(0.9999)$ \\
\hline
\end{tabular}

TABLE 2: Unit root test results of sequence first-order difference.

\begin{tabular}{lcc}
\hline Variable & $\begin{array}{c}\text { ADF } \\
\text { Level }\end{array}$ & $\begin{array}{c}\text { PP } \\
\text { Level }\end{array}$ \\
\hline$l c p_{t}$ & $-5.894742(0.0000)$ & $-36.03728(0.0001)$ \\
\hline$l o p_{t}$ & $-10.05132(0.0000)$ & $-9.229024(0.0000)$ \\
\hline$l g d p_{t}$ & $-4.615071(0.0002)$ & $-7.242270(0.0000)$ \\
\hline
\end{tabular}

\section{The Causal Relationship between Carbon Emissions, International Crude Oil Prices, and GDP}

3.1. Data Source. This paper selected the conversion prices of international crude oil and the domestic annual primary energy carbon emissions of the US to make an empirical analysis. Since the carbon emissions are converted by year according to the energy consumption and current verifiable carbon emissions are calculated by year, in order to maintain the consistency of data sequences, this paper calculated the carbon emissions into the quarterly primary energy consumption since 1983. In addition, international crude oil price data in each trading day were unfixed. Therefore, in order to ensure the consistency of sample data, the adopted international crude oil prices in this paper come from quarterly conversation data of Crude Oil Prices in EIA (Energy Information Administration) database. GDP quarterly data also come from EIA. The sample interval ranges from June 1983 to December 2013. The data source is shown in the following links: primary energy consumption data of America comes from https://www.eia.gov/totalenergy/data/annual/; international crude oil prices data comes from https://www.eia.gov/ petroleum/data.php\#prices.

\subsection{Empirical Test}

3.2.1. Stationarity Test. The commonly accepted ADF (Augmented Dickey-Fuller) and PP (Phillips-Perron) unit root test are adopted to stationary test of carbon emissions $(C P)$, oil prices $(O P)$, and GDP $(G D P)$ series. The test results are shown in Table 1.

The test results in Table 1 show that level value of the three sequences is nonstationary, and further test indicates that $c p, o p$, and $g d p$ sequences are first-order difference stationary. In order to reduce the fluctuations of the data, first-order difference is made on the three sequences. Then three new series $l c p$, lop, and $l g d p$ are obtained, and their unit root test results are shown in Table 2 . 
TABLE 3: Determine Lag Intervals for Endogenous with Lag Length Criteria.

\begin{tabular}{lcccccc}
\hline Lag & $\log \mathrm{L}$ & LR & FPE & AIC & SC & HQ \\
\hline 0 & -1339.964 & NA & 3426841. & 23.56078 & 23.63278 & 23.59000 \\
1 & -1306.761 & 64.07712 & 2241397. & 23.13615 & 23.42418 & 23.25305 \\
2 & -1286.441 & 38.14472 & 1838370. & 22.93756 & 23.44159 & 23.14212 \\
3 & -1195.826 & 165.3319 & 439523.7 & 21.50572 & 22.22577 & 21.79795 \\
4 & -1163.171 & $57.86333 *$ & $290706.8 *$ & 21.09071 & $22.02678 *$ & $21.47061 *$ \\
5 & -1154.389 & 15.09897 & 292582.1 & 21.09454 & 22.24662 & 21.56210 \\
\hline
\end{tabular}

TABLE 4: Estimation results the VAR model.

\begin{tabular}{lccc}
\hline & LCP & LGDP & LOP \\
\hline LCP(-1) & $-0.49474[-6.07864]$ & $-4.770917[-0.67701]$ & $0.453324[0.74409]$ \\
LCP(-2) & $-0.43948[-5.21377]$ & $-1.274873[-0.17468]$ & $0.828137[1.31251]$ \\
LCP(-3) & $-0.408605[-4.88826]$ & $-0.968913[-0.13387]$ & $1.07866[1.72394]$ \\
LCP(-4) & $0.494223[6.13818]$ & $-5.98804[-0.85895]$ & $0.714737[1.18591]$ \\
LGDP(-1) & $0.00123[1.01152]$ & $0.325012[3.08585]$ & $0.000832[0.09136]$ \\
LGDP(-2) & $0.000341[0.27147]$ & $0.406329[3.73285]$ & $0.01335[1.41863]$ \\
LGDP(-3) & $0.001484[1.16965]$ & $-0.181356[-1.65089]$ & $-0.004641[-0.48870]$ \\
LGDP(-4) & $-0.002321[-1.90644]$ & $0.098924[0.93846]$ & $0.018296[2.00765]$ \\
LOP(-1) & $0.009131[0.66567]$ & $2.53743[2.13653]$ & $0.270457[2.63413]$ \\
LOP(-2) & $-0.022643[-1.57017]$ & $-5.005037[-4.00845]$ & $-0.585263[-5.42180]$ \\
LOP(-3) & $-0.007891[-0.52668]$ & $2.230903[1.71979]$ & $0.066615[0.59401]$ \\
LOP(-4) & $-0.026265[-1.81101]$ & $-3.091612[-2.46203]$ & $-0.394997[-3.63852]$ \\
C & $0.107857[0.58783]$ & $42.84598[2.69697]$ & $-2.424158[-1.76502]$ \\
\hline
\end{tabular}

Value in brackets in Table 2 are $\mathrm{P}$ value. ADF and PP values are obviously less than the significant value of $5 \%$, which indicates that the three sequences are stationary.

3.2.2. Estimation of VAR Model. The first issue of the VAR model is to determine Lag Intervals for Endogenous. The larger the Lag Intervals for Endogenous is, the more it can entirely reflect the dynamic nature of the model. But in this case, more parameters will be needed to be estimated to constantly reduce freedom degrees of the model. This is a contradiction in the selection of proper Lag Intervals for Endogenous.

There are many methods that can determine optimal lag period for the VAR model. In comprehensive consideration of selecting Lag Intervals for Endogenous, this paper adopted Lag Length Criteria and Ar Roots Graph to determine Lag Intervals for Endogenous, as shown in Table 3.

According to Table 3, after the comparison of Lag Length Criteria, it can be found that the optimal lag order for the VAR model is 4 . The VAR (lag period is 4th order) model is established with an econometric software, as shown in Table 4.

Value of log likelihood function for the model is relatively large, and AIC value is small, which indicates that the explanatory ability of the model is very strong.

After determining the lag order of 4 , the VAR (4th order) model is reestablished. Then test stationarities of VAR model

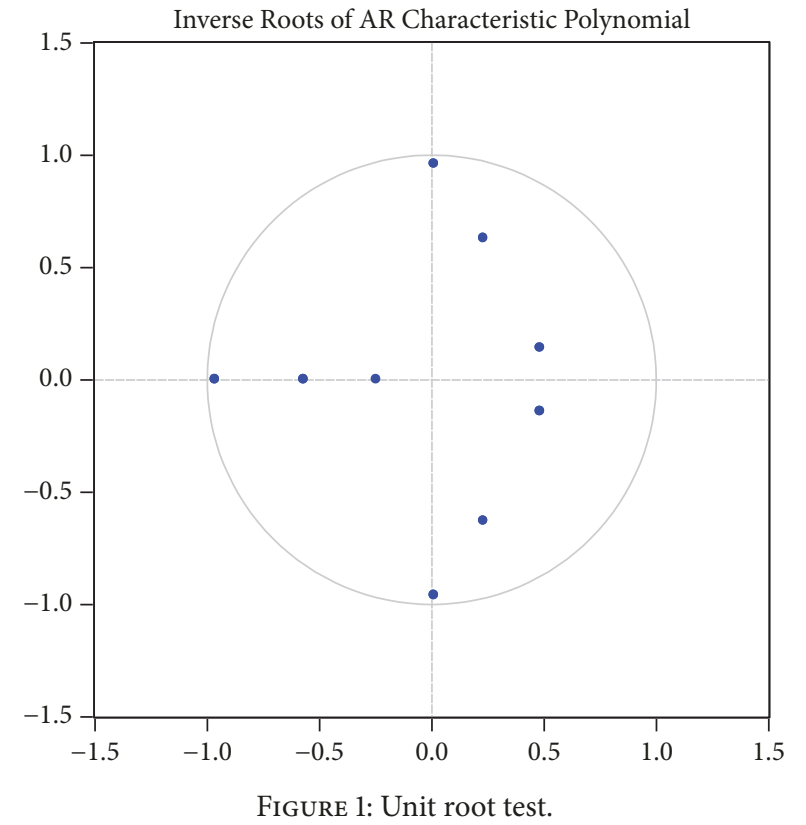

and mod of AR characteristic root reciprocal of VAR model are shown as Figure 1, which indicates that mod of reciprocal of each characteristic root is in the circle. That is to say lag order of 4 is appropriate, and the established VAR model is stable after going through stability test. 
TABLE 5: Results of cointegration test.

(a)

\begin{tabular}{lcccc}
\hline \multicolumn{5}{c}{ Unrestricted Cointegration Rank Test (Trace) } \\
\hline Hypothesized & & Trace & 0.05 & \\
No. of CE $(\mathrm{s})$ & Eigenvalue & Statistic & Critical Value & \\
\hline None $*$ & 0.4252 & 115.4481 & 29.7971 & 0 \\
At most $1 *$ & 0.2631 & 50.0979 & 15.4947 & 0 \\
At most $2 *$ & 0.1124 & 14.0742 & 3.8415 & 0.0002 \\
\hline
\end{tabular}

Trace test indicates 3 cointegrating eqn(s) at the 0.05 level.

* denotes rejection of the hypothesis at the 0.05 level.

$* *$ MacKinnon-Haug-Michelis (1999) p-values.

(b)

\begin{tabular}{|c|c|c|c|c|}
\hline \multicolumn{5}{|c|}{ Unrestricted Cointegration Rank Test (Maximum Eigenvalue) } \\
\hline Hypothesized & & Max-Eigen & 0.05 & \\
\hline No. of CE(s) & Eigenvalue & Statistic & Critical Value & Prob. $* *$ \\
\hline None $*$ & 0.4252 & 65.3502 & 21.1316 & 0 \\
\hline At most $1 *$ & 0.2631 & 36.0237 & 14.2646 & 0 \\
\hline At most $2 *$ & 0.1124 & 14.0742 & 3.8415 & 0.0002 \\
\hline
\end{tabular}

Max-eigenvalue test indicates 3 cointegrating eqn(s) at the 0.05 level.

* denotes rejection of the hypothesis at the 0.05 level.

$* *$ MacKinnon-Haug-Michelis (1999) p-values.

3.2.3. Cointegration Test. The key of cointegration test lies in selecting proper form of cointegration test and lag order. Cointegration relationship between variables in the VAR model is generally tested with the Johnsen (1988) and Juselius (1990) method. Here the selected sequences are linear trend terms, and then the test form of cointegration equation is only intercept.

Johansen cointegration test on oil prices, GDP and carbon emissions (Table 5) shows that, in both trace and maximum eigenvalue test, test results are to accept the null hypothesis, under the 5\% level, and two positive relationships exist. This means there are stable and long-term equilibrium relationships among the variables. On the premise of the existence of cointegration relationships, VEC modeling can be further conducted.

3.2.4. VECM Estimation and Analysis. Cointegration analysis demonstrates that oil prices, GDP, and carbon emissions do have long-run equilibrium relationships, but, in the short term, the three are in disequilibrium. The short-term imbalance and dynamic structure can be expressed as VECM. Since the lag order of VAR is 4, VECM's lag order should be 3 . Accordingly, VEC model is established with an econometric software.

As the second cointegration equation shows, there is no correlation between GDP and oil prices, which is inconsistent with general economic situation. Therefore, with first equation treated as the cointegration equation of VEC model, the equation's results are shown as Table 6.

The cointegration equation is

$$
\begin{aligned}
l c p_{t-1}= & -0.015342 \operatorname{lgd} p_{t-1}+0.743478 \operatorname{lop} p_{t-1} \\
& +1.126692
\end{aligned}
$$

TABLE 6: Results of cointegration equation.

\begin{tabular}{lc}
\hline Cointegrating Eq: & CointEq1 \\
\hline LCP $(-1)$ & 1 \\
LGDP(-1) & $-0.015342[-0.00491]$ \\
LOP $(-1)$ & $0.743478[0.08675]$ \\
C & 1.126692 \\
\hline
\end{tabular}

From this equation it can be seen that, other things equal, each percentage-point increase in oil prices will cause the increase of 0.73478 percentage points in carbon emissions, and each percentage-point increase in GDP will cause the decrease of 0.015342 percentage points in carbon emissions.

VECM is as follows:

$$
\begin{aligned}
& {\left[\begin{array}{c}
\Delta l c p_{t} \\
\Delta l g d p_{t} \\
\Delta l o p_{t}
\end{array}\right]} \\
& =\left[\begin{array}{c}
0.0047 \\
0.7334 \\
-0.1679
\end{array}\right] \\
& +\left[\begin{array}{ccc}
-0.9617 & 4.0004 & 1.3081 \\
-0.0004 & -0.6408 & -0.0294 \\
0.0764 & 7.5017 & 0.8805
\end{array}\right]\left[\begin{array}{c}
\Delta l c p_{t-1} \\
\Delta l g d p_{t-1} \\
\Delta l o p_{t-1}
\end{array}\right]
\end{aligned}
$$


TABLE 7: VECM estimation results and test.

\begin{tabular}{lccc}
\hline Error Correction: & D(LCP) & D(LGDP) & D(LOP) \\
\hline CointEq1 & $-0.104234[-2.58593]$ & $-7.268381[-2.24355]$ & $-2.133611[-7.90997]$ \\
D(LCP(-1)) & $-0.961687[-23.9237]$ & $4.000415[1.23820]$ & $1.308053[4.86264]$ \\
D(LCP(-2)) & $-0.954550[-24.0919]$ & $4.273666[1.34204]$ & $0.803946[3.03216]$ \\
D(LCP(-3)) & $-0.919406[-31.5065]$ & $4.670270[1.99125]$ & $0.556109[2.84777]$ \\
D(LGDP(-1)) & $-0.000414[-0.31978]$ & $-0.640796[-6.16527]$ & $-0.029396[-3.39685]$ \\
D(LGDP(-2)) & $-0.000291[-0.20219]$ & $-0.152107[-1.31289]$ & $-0.014040[-1.45546]$ \\
D(LGDP(-3)) & $0.001903[1.50015]$ & $-0.251021[-2.46167]$ & $-0.019500[-2.29678]$ \\
D(LOP(-1)) & $0.076443[3.11551]$ & $7.501668[3.80402]$ & $0.880550[5.36292]$ \\
D(LOP(-2)) & $0.045991[2.36590]$ & $1.857454[1.18885]$ & $0.308622[2.37246]$ \\
D(LOP(-3)) & $0.030246[1.86907]$ & $3.918942[3.01310]$ & $0.396354[3.66007]$ \\
C & $0.004684[0.04941]$ & $0.733444[0.09628]$ & $-0.167900[-0.26471]$ \\
\hline R-squared & 0.957803 & 0.390277 & 0.551367 \\
\hline Log likelihood & & -1223.996 & 21.35586 \\
Akaike information criterion & & 22.20116 & \\
Schwarz criterion & & & \\
\hline
\end{tabular}

(8)

The data in Table 7 show that fitting degree of VEC model $\mathrm{R}^{2}>0.5$, and AIC and SC criteria values are relatively small, which indicates the reasonability of the model estimation.

Zero average line represents a stable and long-term equilibrium relationship among variables. There was a large fluctuation at the end of 2008, which shows that the shortterm fluctuation at that period significantly deviated from the long-term equilibrium relationship. The short-term fluctuation effect is a sharp drop in international oil prices caused by the financial crisis in 2008, shown as Figure 2.

3.2.5. Granger Causality Test. Cointegration test indicates a long-term equilibrium relationship between the two variables, but, in terms of causal relationship, further testing is needed. If variable $A$ is helpful in predicting $B$, namely, the regression of $B$ is based on past values of $B$ and past values of $A$ are added, this can greatly enhance the explanatory ability of the regression. Then A can be called Granger cause of B; otherwise it can be called non-Granger cause.

$P$ value is less than the significant level of $5 \%$, which indicates the need to accept the null hypothesis, namely the existence of Granger cause. As the results shown in Table 8,

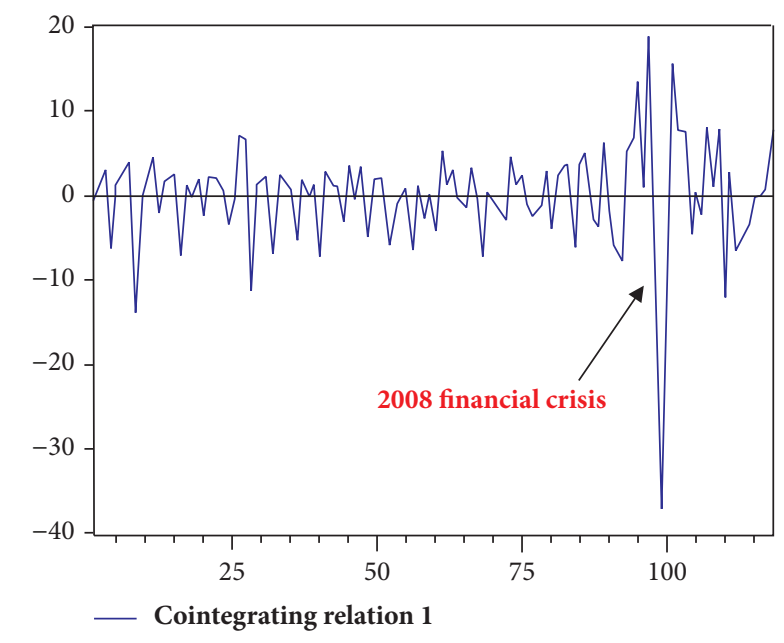

FIgURE 2: Cointegration relationship graph.

except that LGDP and LCP are not Granger causes of each other, all the others exist Granger causality relationship. Therefore, GDP and carbon emission are the Granger causes of oil prices; oil prices are the Granger cause of both carbon emissions and GDP. Granger causality test shows that there are Granger causalities among changes in oil prices, GDP, and carbon emissions in the short term, and there is certain reciprocity among the three factors.

3.2.6. VECM Stability Test. Root of 4 residual stability test results in 1, and root of other residual stability test results in less than 1. So the VECM model satisfies the stability condition. At the same time, variable autocorrelation test shows that, except for LCP, others do not have autocorrelation 
TABLE 8: Granger causality test.

\begin{tabular}{|c|c|c|c|c|}
\hline \multicolumn{4}{|c|}{ Dependent variable: $\mathrm{D}(\mathrm{LCP})$} & \multirow{2}{*}{ The primary hypothesis } \\
\hline Excluded & Chi-sq & df & Prob. & \\
\hline $\mathrm{D}(\mathrm{LGDP})$ & 3.337504 & 3 & 0.3425 & Accept \\
\hline $\mathrm{D}(\mathrm{LOP})$ & 9.756523 & 3 & 0.0208 & Refuse \\
\hline All & 16.11858 & 6 & 0.0131 & \\
\hline \multicolumn{5}{|c|}{ Dependent variable: D(LGDP) } \\
\hline Excluded & Chi-sq & df & Prob. & \\
\hline $\mathrm{D}(\mathrm{LCP})$ & 4.679288 & 3 & 0.1968 & Accept \\
\hline $\mathrm{D}(\mathrm{LOP})$ & 22.11808 & 3 & 0.0001 & Refuse \\
\hline All & 26.50551 & 6 & 0.0002 & \\
\hline \multicolumn{5}{|c|}{ Dependent variable: $\mathrm{D}(\mathrm{LOP})$} \\
\hline Excluded & Chi-sq & df & Prob. & \\
\hline $\mathrm{D}(\mathrm{LCP})$ & 29.02233 & 3 & 0.0000 & Refuse \\
\hline $\mathrm{D}(\mathrm{LGDP})$ & 18.91076 & 3 & 0.0003 & Refuse \\
\hline All & 42.91822 & 6 & 0.0000 & \\
\hline
\end{tabular}

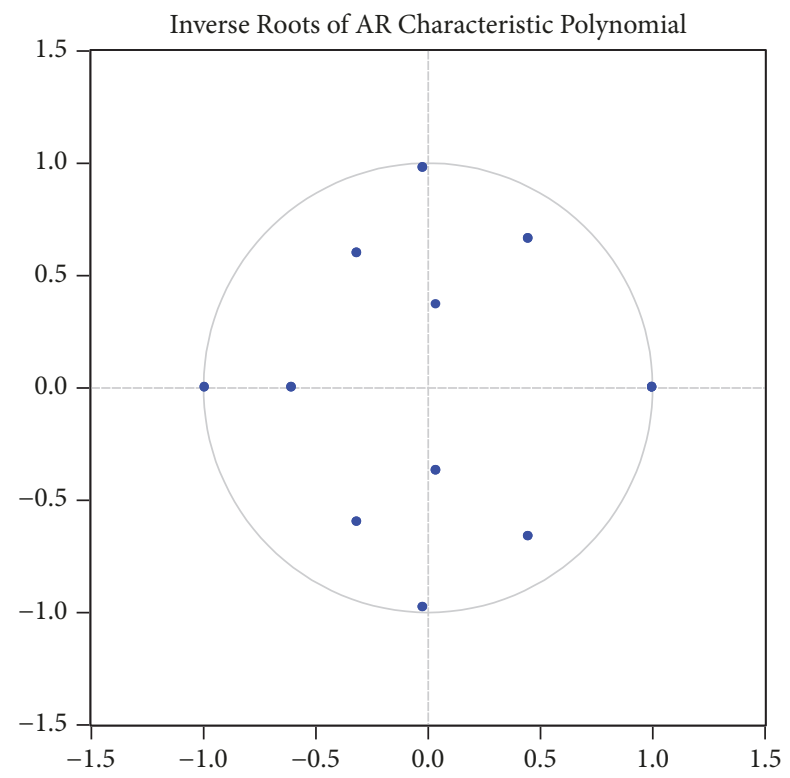

FIgURE 3: Residual stability test of ECM model.

(Figures 3-4). On the whole, the VECM model has good effects.

\subsubsection{Impulse Response Function and Variance Decomposition}

(1) Impulse Response Function. In order to analyze dynamic effects of the model responding to certain shocks as well as how the effects are among the three variables, further analysis is made through impulse response function and variance decomposition based on VECM, and the results for 10 periods are obtained.

According to Granger test results, in consideration of the effects of standard deviation on oil prices, effects of oil prices on GDP and carbon emissions are totally different. But in general, these fluctuations are divergent; that is to say, the impacts of oil price fluctuation on GDP and carbon emissions are persistent.

As shown in Figure 5(a), after analysis of the effects of oil price shock, it is found that positive shock has large impact. Oil prices decline rapidly after a positive shock, reach the lowest point in the third period, then rise slowly, reach the peak in the 7 th period, and then remain at a stable level. This suggests that positive shock of oil prices has significant influence on its own increasing, and the significance influence has relatively long sustained effectiveness.

Figure 5(b) is the impulse response function diagram of GDP changes caused by oil price shocks. As seen in the figure, the first positive shock in the first period causes GDP fluctuation, and GDP reaches the peak at the second period. Then GDP quickly declines to the lowest point in the third period, and after that returns to a stable condition. This shows that oil price shock can be shortly transferred to GDP, and has relatively large impacts on GDP in the short term, but GDP becomes stable since the fourth period. Oil price shock has the short-term promoting effect on GDP fluctuation, and this effect tends to be gentle in the long term.

Figure 5(c) is the impulse response function of carbon emission changes caused by oil price shock. As shown in the figure, after a positive shock in the first period, carbon emissions decline to the lowest point in the third period and begin to rise slowly. Then carbon emissions reach the peak at seventh period and stay at a stable level. This shows that a positive shock on oil prices can cause changes in carbon emissions, and its effect becomes gentle since the seventh period. It can be noticed that oil price shock has relatively large effect on carbon emissions in the short term, and the effect lasts for seven periods.

Generally speaking, oil price shock has large effects on GDP and carbon emissions in the short term, but the effects are gentle in the long term.

(2) Variance Decomposition. Impulse response function is adopted to reflect shock effect of a system on an internal variable, and variance decomposition refers to the decomposition of mean square error into contributions of each variable. Variance decomposition can be applied to analyze the influence of each variable's update on other variables, which shows relative effects. With an econometric software, variance decomposition results are obtained, as shown in Figure 6.

According to Figure 6(a), in LCP predicted variance, contribution of LCP change begins to gradually decline from the first period, reaches $92 \%$ in the fourth period, begins to rise and gradually returns to a stable level. LGDP and LOP's contribution rates, respectively, rise to $7 \%$ and $8 \%$ at the first and fourth periods and then maintain stability until the tenth period. In Figure 6(b), for predicted variance of LGDP, contribution rate of LGDP change declines from $98 \%$ in the first period to $84 \%$ in the sixth period and then maintains stability until the tenth period. But LCP's contribution remains at about $4 \%$ throughout the periods. LOP's contribution rate slowly rises from the first period to 

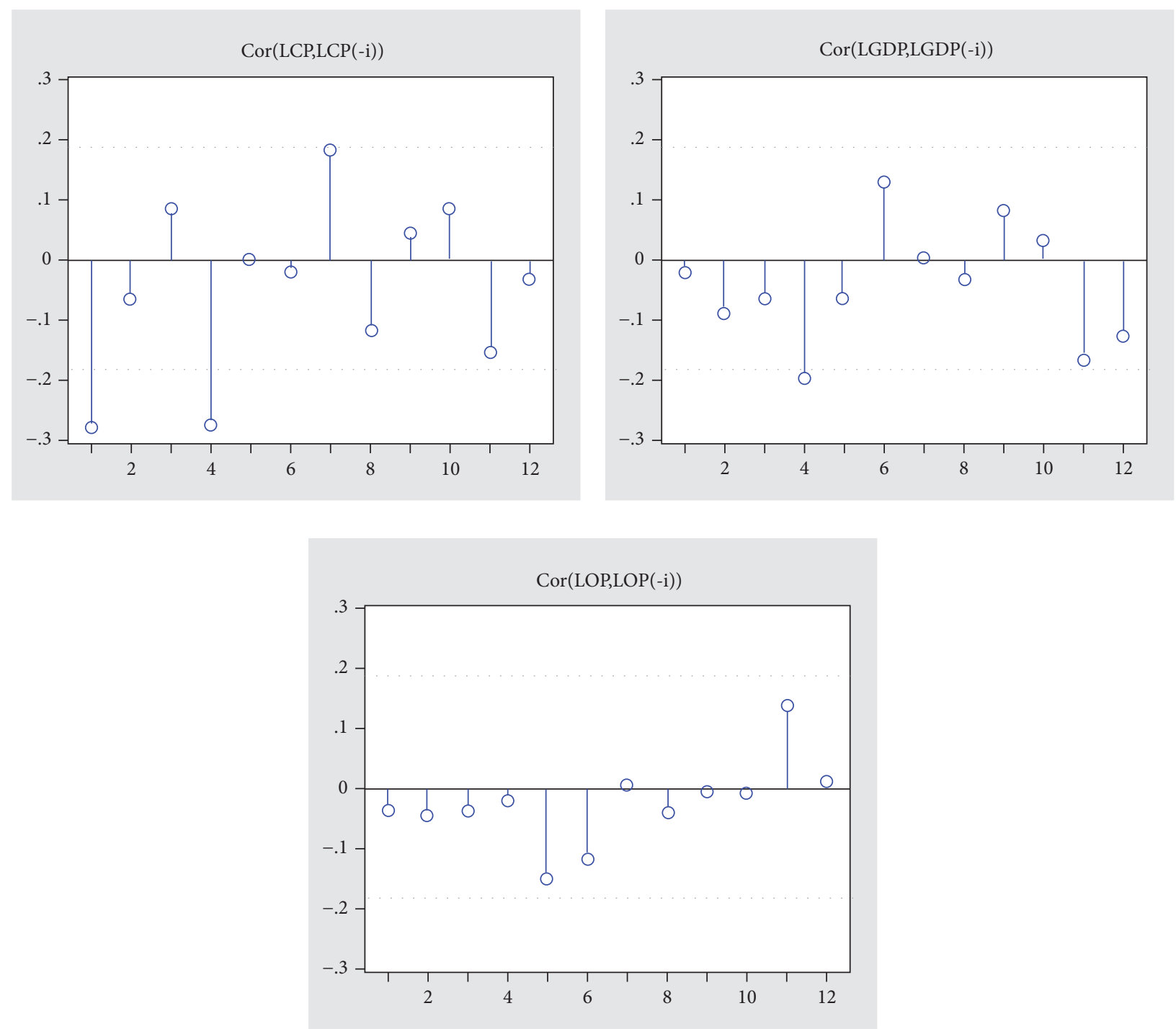

FIGURE 4: VECM autocorrelation diagram.

$12 \%$ in the sixth period and then maintains stability until the tenth period. In Figure 6(c), for predicted variance of LOP, contribution of LOP declines from $82 \%$ in the first period to $80 \%$ in the second period, gradually increases to the peak of $83 \%$ in the fourth period, and then stably declines to $78 \%$ in the tenth period. LGDP's contribution rate gently declines from $18 \%$ in the first period to $16 \%$ in the third period and then slightly rises to $19 \%$ until the last period. Contribution rate of LCP quickly rises from $1 \%$ in the first period to $7 \%$ in the second period and then basically maintains stability.

In summary, it can be seen that, in the short term, the oil prices have great influence on GDP and carbon emissions. In the long run, the influence is leveling off. As presented in the model, the growth of oil price is related to not only the current variables, but also the variables in the lag period.

\section{Conclusions}

This paper established the correlation model of American primary energy carbon emissions, GDP and WTI crude oil prices and examined the causal relationships among the three factors on the basis of the VEC model. The results demonstrate that, in both the short term and long term, oil price fluctuation is the reason why carbon emissions change, while the GDP fluctuation is not the reason for the growth of carbon emissions.

(1) Through Granger analysis of the VEC model, the US GDP and carbon emissions are not Granger causes of each other. This shows that the growth of carbon emissions in the US does not necessarily promote GDP growth, and economic growth in the country does not intensify the excessive consumption of energy to cause plenty of carbon emissions. This is also proved by the fact that the country's 


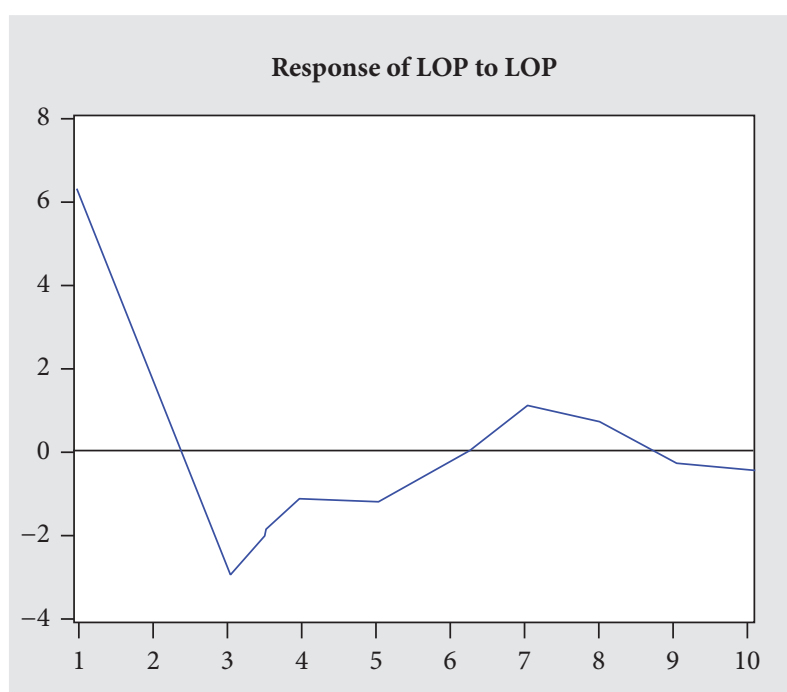

(a)

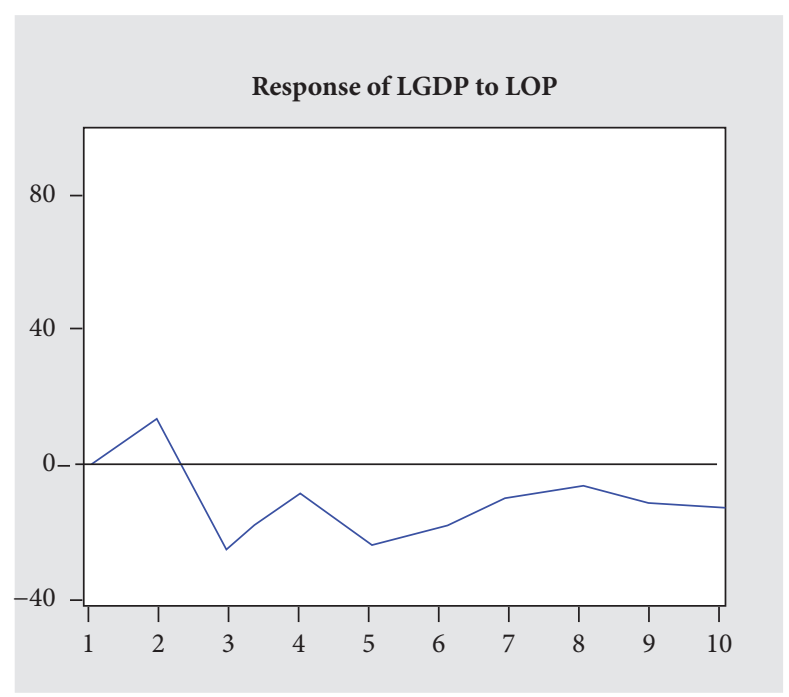

(b)

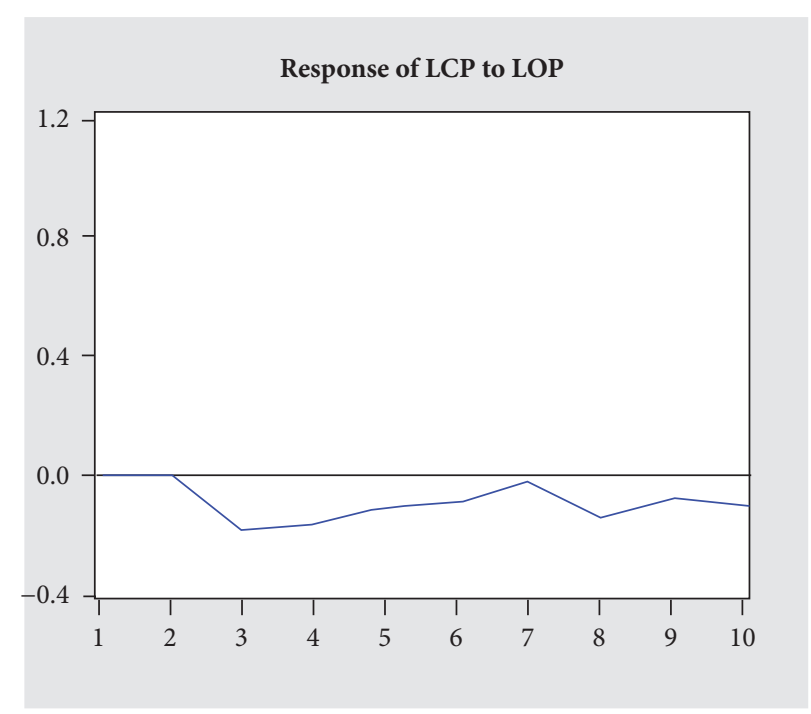

(c)

FIGURE 5: Impulse response.

economic growth in recent years mainly relies on the vigorous development of high-tech industry.

(2) According to impulse response function analysis, it is found that carbon emission and oil prices present negative effects. A positive shock of oil prices has reverse effect on carbon emissions. Influenced by the factor of oil price, the high oil prices will slow down the increasing speed of oil demand, to further cause the declining proportion of oil in energy structure. Energy consumption will turn to new energy and renewable energy to replace the energy conversion. This is consistent with the energy consumption in the time of high oil price. The rise in oil prices causes the decline in fossil energy consumption and further leads to the decline of carbon emissions.

(3) The VEC empirical analysis indicates that the oil price impact will produce great influence on GDP and carbon emissions in the short term, but, in the long term, the influence will tend to be gentle.

In conclusion, the correlations among the US GDP, oil price fluctuations, and carbon emissions are relatively complex, and there exists an asymmetric interaction mechanism. A positive shock of oil prices can have a negative impact on carbon emissions, and GDP growth does not lead to the growth of carbon emissions.

\section{Data Availability}

The data source is shown in the following links: primary energy consumption data of America comes from https:// www.eia.gov/totalenergy/data/annual/; international crude oil prices data comes from https://www.eia.gov/petroleum/ data.php\#prices. 
Variance Decomposition of LCP

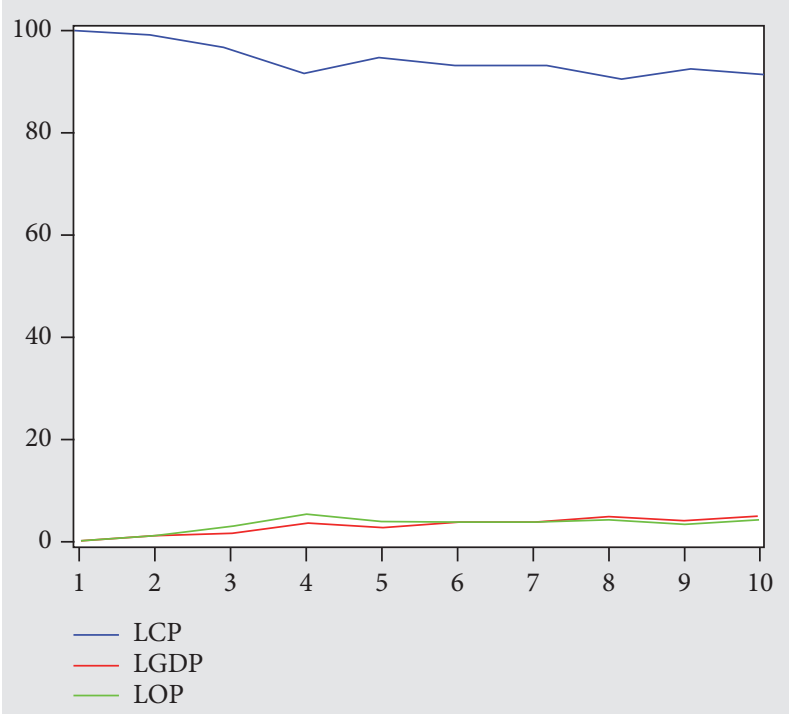

(a)

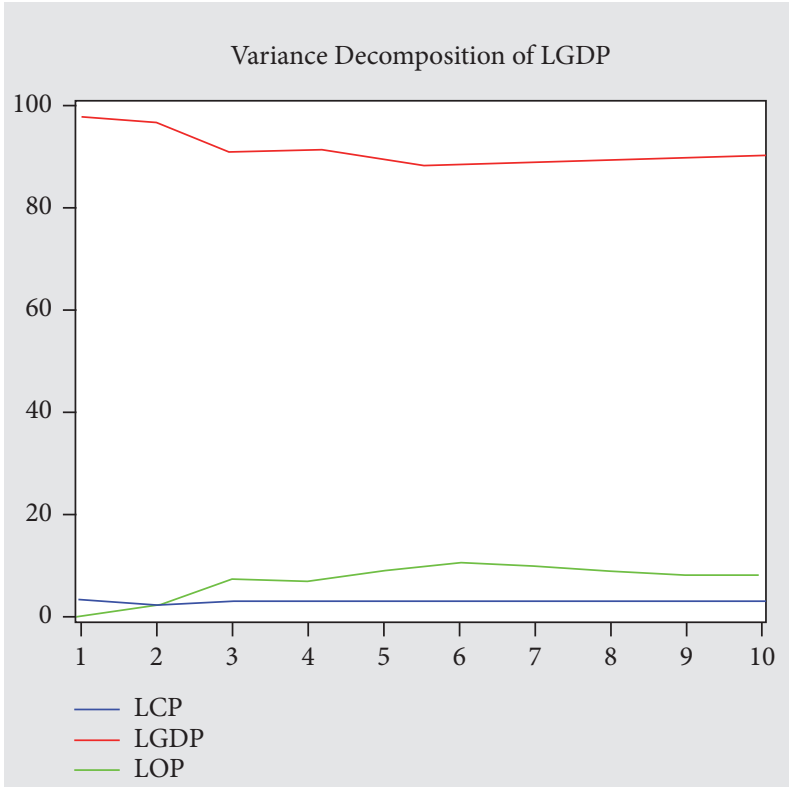

(b)

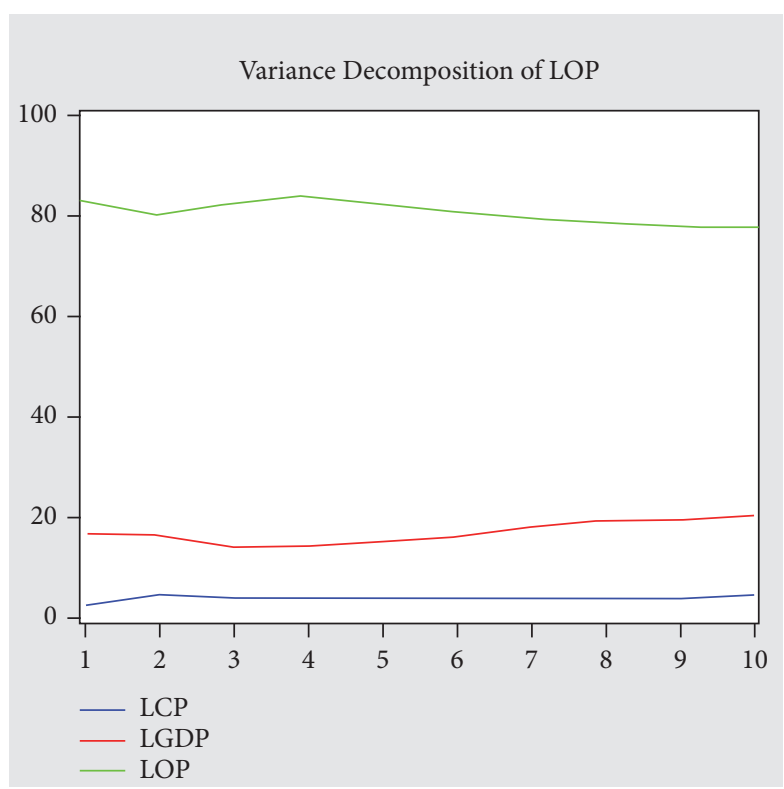

(c)

FIgURE 6: Variance decomposition.

\section{Conflicts of Interest}

The author declares that there are no conflicts of interest.

\section{Acknowledgments}

This paper was supported by the National Natural Science Foundation of China, no. 51276081; National Social Science Fund of China, no. 12\&ZD062; Brand Professional Building in Jiangsu Higher Education Institutions, PPZY2015A090; Science and Technology Support Project (Social Development) in Jiangsu Province, no. BE2014692; Science and
Technology Support Plan (Social Development) in Zhenjiang City, no. SH2015018.

\section{References}

[1] J. Kraft and A. Kraft, "On the relationship between energy and GNP," Journal of Energy and Development, vol. 3, no. 2, pp. 401403, 1978.

[2] H. Iwata, K. Okada, and S. Samreth, "Empirical study on the environmental Kuznets curve for CO2 in France: The role of nuclear energy," Energy Policy, vol. 38, no. 8, pp. 4057-4063, 2010. 
[3] F. Zhenxin, X. Xiaojing, and W. Shuping, "The Influence of Economic Development and Industrial Structure to Carbon Emission Based on China's Provincial Panel Data," Chinese Journal of Management Science, vol. 20, no. 3, pp. 161-166, 2012.

[4] L. boqiang and J. zhujun, "Influencing Factors and Kuznets curve prediction of Chinese $\mathrm{CO}_{2}$," Management World, vol. 4, pp. 27-35, 2009.

[5] Z. Ren and Y.-B. Zhou, "Economie growth and waste gas pollution in Bohai area," China Population Resources and Environment, vol. 19, no. 2, pp. 63-68, 2009.

[6] U. Soytas, R. Sari, and B. T. Ewing, "Energy consumption, income, and carbon emissions in the United States," Ecological Economics, vol. 62, no. 3-4, pp. 482-489, 2007.

[7] N. Bashiri Behmiri and J. R. Pires Manso, "Crude oil conservation policy hypothesis in OECD (organisation for economic cooperation and development) countries: A multivariate panel Granger causality test," Energy, vol. 43, no. 1, pp. 253-260, 2012.

[8] S. Hammoudeh, D. K. Nguyen, and R. M. Sousa, "Energy prices and $\mathrm{CO} 2$ emission allowance prices: A quantile regression approach," Energy Policy, vol. 70, pp. 201-206, 2014.

[9] S. Rajaratnam, "Fossil fuel based $\mathrm{CO}_{2}$ emissions, economic growth, and world crude oil price nexus in the United States," Article ID 29574, Munich Personal RePEc Archive, 2007, 12, Paper No.29574, http://mpra.ub.uni-muenchen.de/29574/.

[10] M. Jisheng and H. Hao, "Based on the VAR (vector auto regression) dynamic analysis on the dynamic analysis the relationship between carbon emission and economic growth in China based on VAR," Inquiry into economic issues, vol. 5, pp. 20-25, 2011.

[11] J. luo, "An empirical investigation of the causal relationship between carbon dioxide emissions and GDP growth in china," Journal of Zhengzhou Institute of Aeronautical Industry Management, vol. 10, no. 28, pp. 24-27, 2010.

[12] F. Jiafeng, G. Qingxian, and S. Huading, "Empirical Study on the $\mathrm{CO}_{2}$ Environmental Kuznets Curve Based on Production and Consumption-based $\mathrm{CO}_{2}$ Emissions," Advances in climate change research, vol. 11, no. 4, pp. 376-381, 2008.

[13] L. Han and L. Yang, "The Relationship between Economic Growth and Environmental Quality: An Empirical Test of Environmental Kuznets Curve of $\mathrm{CO}_{2}$," in Economic Theory and Business Management, vol. 3, p. 11, 5, 2009.

[14] X. Zhang and X. Cheng, "Energy consumption, carbon emissions, and economic growth in China," Ecological Economics, vol. 68, no. 10, pp. 2706-2712, 2009. 


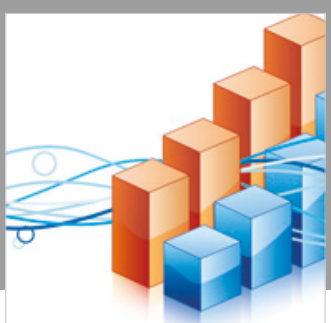

Advances in

Operations Research

\section{-n-m}
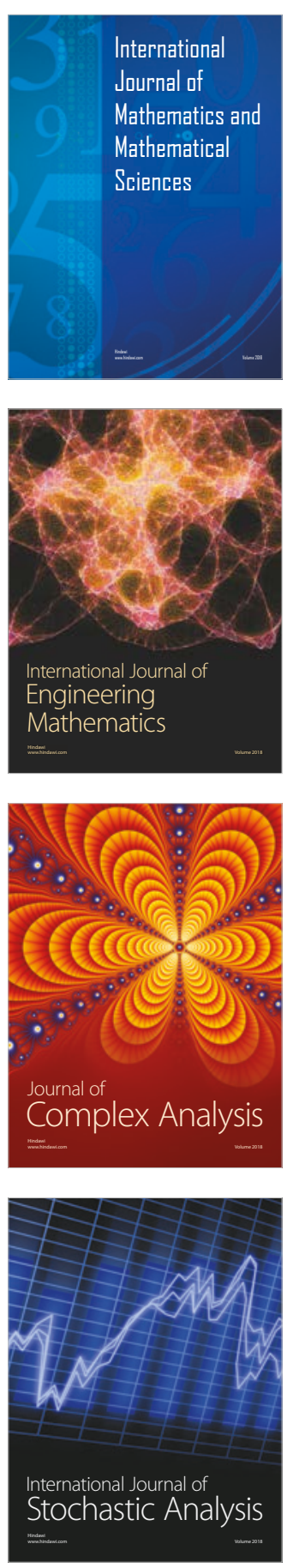
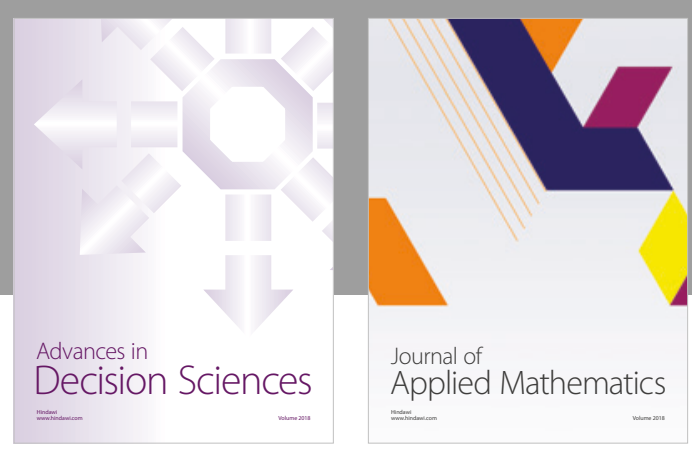

Journal of

Applied Mathematics
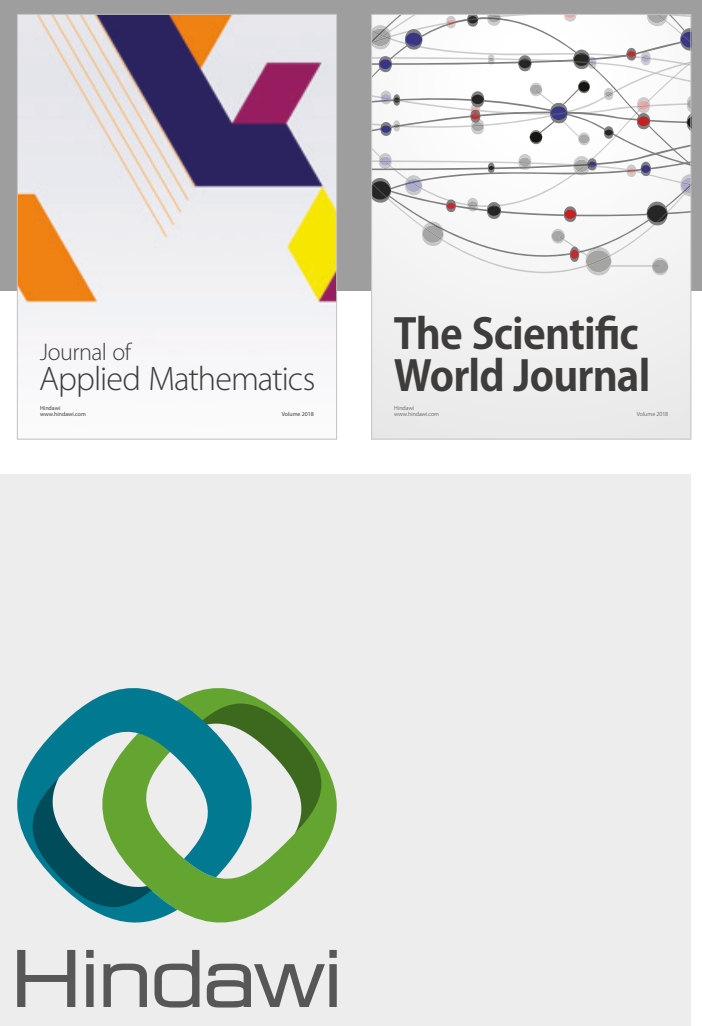

Submit your manuscripts at

www.hindawi.com

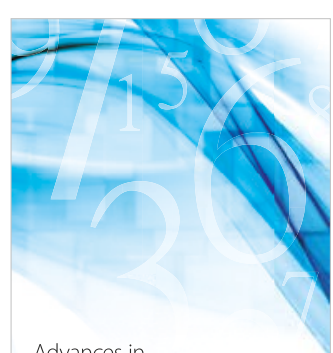

Advances in
Numerical Analysis
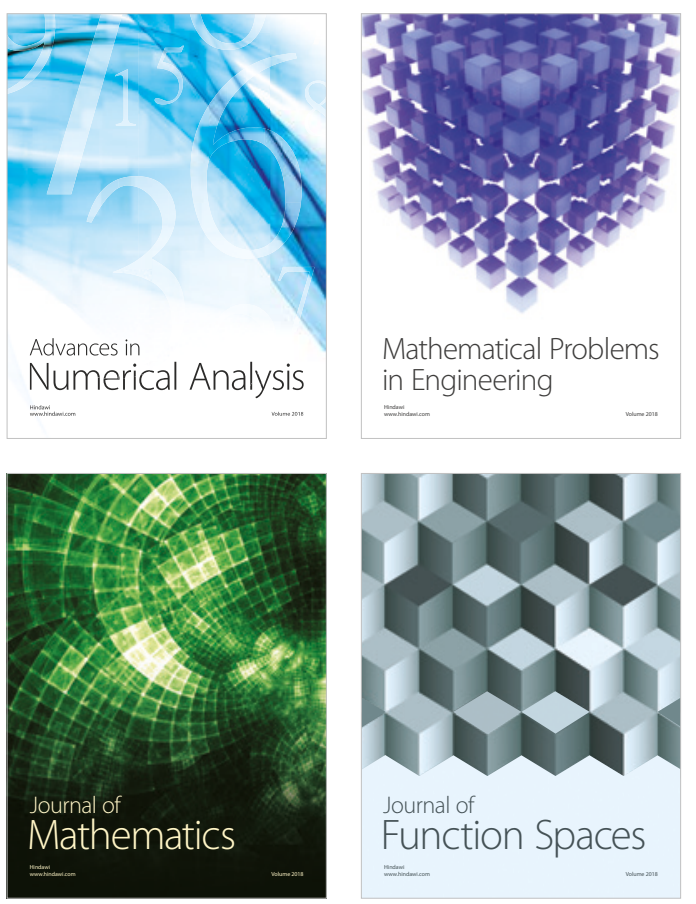

Mathematical Problems in Engineering

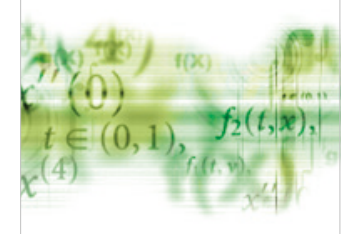

International Journal of

Differential Equations

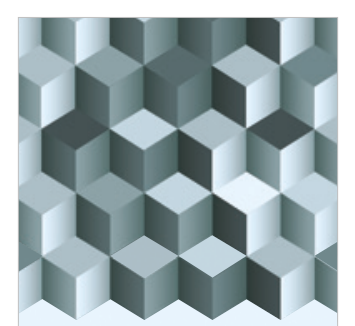

Journal of

Function Spaces

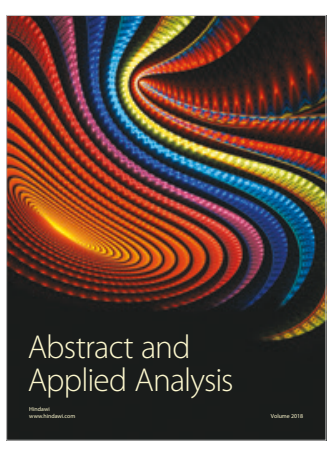

The Scientific

World Journal

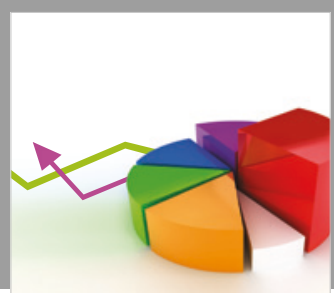

Journal of

Probability and Statistics
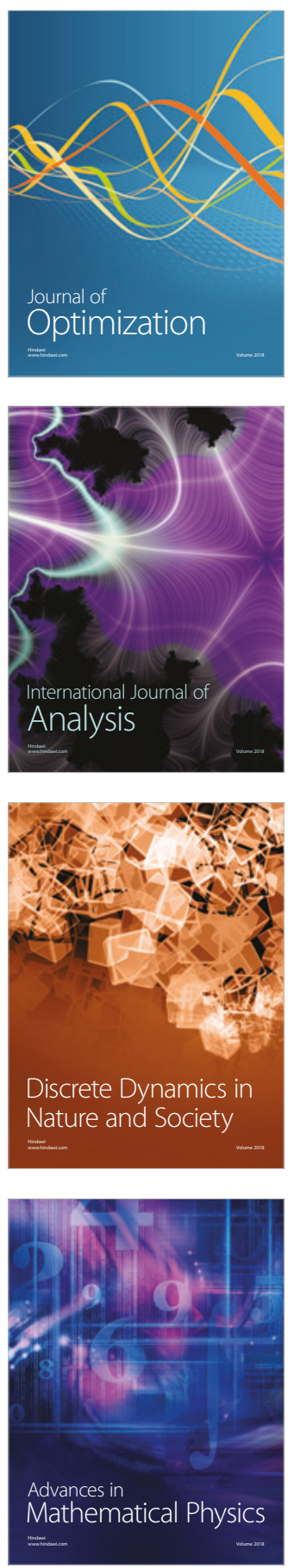